\title{
PENERAPAN FUZZY TOPSIS UNTUK PEMILIHAN PEMASOK PADA DEPARTEMEN SUPPLY CHAIN DI PERUSAHAAN PENGOLAHAN AIR KABUPATEN TANGERANG
}

\author{
${ }^{1}$ Diah Septiyana, ${ }^{2}$ Galang P. N. Hakim \\ ${ }^{1,}$ Program Studi Teknik Industri, Fakultas Teknik, Universitas Muhamadiyah Tangerang \\ ${ }^{2,}$ Program Studi Teknik Elektro, Fakultas Teknik, Universitas Mercu Buana
}

\begin{abstract}
A b s t r a k
Dalam proses pengadaan di departemen Supply Chain metode pemilihan pemasok sangatlah problematic karena ketidakpastian pemilihan pemasok yang diakibatkan oleh adanya ego dan perasaan manusia sebagai salah satu penentu keputusan. Oleh karena itu, dengan adanya penggunaan metode FUZZY TOPSIS untuk memecahkan masalah pemilihan pemasok ini. Metode FUZZY TOPSIS menentukan pemasok yang memiliki kinerja terbaik dengan menggunakan kriteria yang diberikan oleh pengguna. Dengan menggunakan metode ini keputusan pemilihan pemasok dapat melakukan secara otomatis menggunakan sistem IT pada perusahaan masing-masing, sehingga dapat meminimalkan masalah pengguna dari memilih pemasok terbaik. Contoh dari ini adalah proyek oleh Perusahaan Pengolahan Air di Kabupaten Tangerang untuk menemukan pemasok terbaik dalam sistem distribusi air. Untuk pemasok yang DEI, HP, dan KSP dan diberikan criteria pengguna seperti "Commercial by Costumer", "Technical Proposal”, "Work Plan \& methodology", dan "Staff Competence”. Dengan menggunakan criteria pengguna untuk membuat matriks keputusan sebagai masukan untuk FUZZY TOPSIS. Hasilnya adalah pemasok KSP menunjukkan performa terbaik dengan nilai 0.50078 lebih baik dari pemasok lainnya.
\end{abstract}

Kata Kunci : fuzzy topsis, supply chain, ERP, pemasok.

\section{PENDAHULUAN}

Dalam setiap perusahaan di dunia ada departemen khusus yang berhubungan dengan perusahaan lain untuk menyediakan sumber daya yang dibutuhkan. Sumber daya tersebut dapat digunakan sebagai bahan untuk menghasilkan hal-hal lain sebagai pendapatan bagi perusahaan, atau hanya sebagai alat untuk membantu dengan rutinitas pekerjaan sehari-hari. Departemen itu adalah sebagai departemen pengadaan. Supply Chain sebagai fungsi dari departemen pengadaan (Procurement), fungsi utama mereka adalah untuk melakukan penyediaan sumber daya (Selanjutnya akan menggunakan kata "material" untuk menggantikan kata "sumber daya" untuk menghindari konsep rancu dengan "sumber daya manusia" atau "sumber daya lainnya ") dan melakukan pemilihan supplier untuk menemukan kinerja pemasok yang terbaik untuk meminimalkan biaya penyediaan bahan. Fungsi lain dari Supply Chain Management adalah untuk mendistribusikan material untuk setiap departemen yang memerlukan dengan efektif dan hati-hati sehingga memberikan nilai tambah bagi produk perusahaan (Dania Arini, 2015).

Dalam makalah ini kita mempelajari tentang metode pemilihan pemasok untuk menemukan performa pemasok terbaik. Dari kasus di Perusahaan Pengolahan Air di Kabupaten Tangerang sebagai perusahaan air yang menyediakan air untuk rutinitas sehari-hari di seluruh kabupaten Tangerang. Perusahaan ini masih menggunakan manual metode pemilihan pemasok berdasarkan keputusan manusia, oleh karena itu ini adalah masalah yang sangat serius karena keputusan manusia dapat berubah sesuai dengan minat mereka. Penelitian ini merupakan awal untuk mengembangkan sebuah sistem pakar dengan tujuan untuk mengintegrasikan dengan sistem ERP (Enterprise Resource Planning) yang telah diimplementasikan di Perusahaan ini. Dengan sistem ini kami berharap dapat meminimalkan keputusan manusia dari memilih pemasok terbaik. 
Sebagai solusi untuk masalah keputusan manusia manual ini, kami mengusulkan metode pemilihan pemasok menggunakan FUZZY TOPSIS (Technique for Preference Order by Similarity to Ideal Solution). FUZZY TOPSIS merupakan salah satu metode yang paling popular dan telah terbukti memberikan hasil yang dapat membantu dalam berbagai bidang aplikasi (E. N. Madi et al, 2015). Metode ini dikembangkan untuk memecahkan masalah MCDM (Multi Criteria Decision Making) dengan prinsip dasar untuk memilih alternatif yang memiliki jarak terpendek dari solusi ideal positif (terbaik) dan jarak terjauh dari solusi ideal negatif (terburuk).

Dengan menggunakan metode ini keputusan pemasok dapat melakukan secara otomatis menggunakan sistem IT di perusahaan masing-masing. TOPSIS kabur menentukan yang pemasok memiliki kinerja terbaik menggunakan kriteria yang diberikan menentukan oleh pengguna. Pada penelitian ini terdiri dari 3 pemasok yaitu DEI, HP, and KSP dengan 5 kriteria contoh yang diberikan sesuai dengan Pengguna seperti "Commercial by Costumer", "Technical Proposal", "Work Plan \& methodology", dan "Staff Competence".

\section{METODE PENELITIAN}

\section{- ALGORITMA FUZZY TOPSIS}

Sebuah metode Fuzzy TOPSIS didasarkan pada konsep bahwa alternatif yang dipilih harus memiliki jarak geometris terpendek dari solusi ideal positif dan juga memiliki jarak geometris terpanjang dari solusi ideal negatif. Oleh karena itu metode ini membandingkan satu set alternative dengan mengidentifikasi bobot untuk setiap kriteria, normalisasi nilai untuk setiap criteria dan menghitung jarak geometris antara masing-masing alternatif yang terburuk dengan alternatif yang ideal, sehingga akan menghasilkan nilai terbaik di setiap kriteria. Algoritma Fuzzy dapat dilihat pada gambar 1 . 


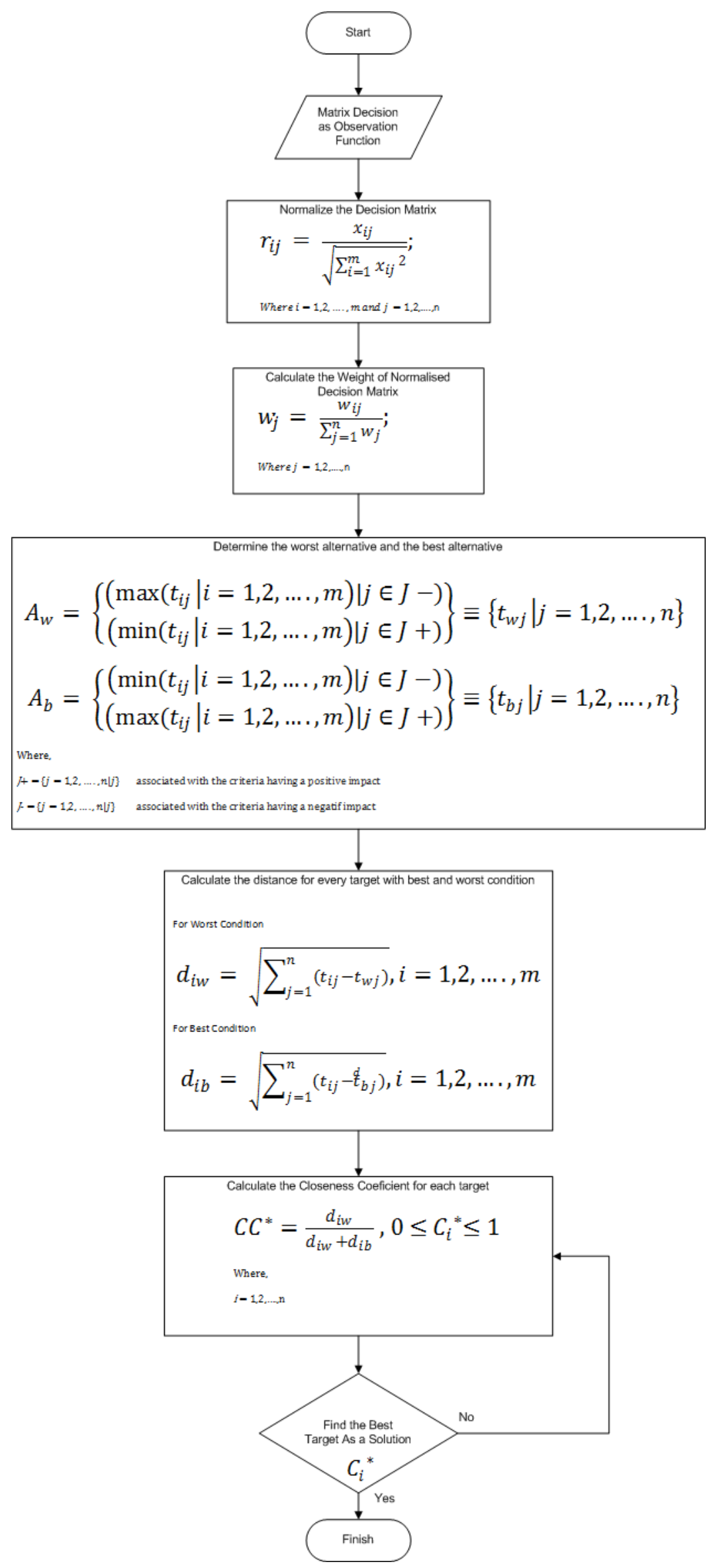

Gambar 1. Algoritma Fuzzy Topsis 


\section{HASIL DAN PEMBAHASAN}

Menggunakan algoritma Fuzzy TOPSIS maka dapat disimulasikan dan dihitung nilai untuk setiap masing-masing pemasok untuk setiap kriteria-kriteria yang diberikan oleh pengguna.

\section{A. Matriks Keputusan}

Menggunakan pengamatan dan kuesioner yang kami kumpulkan untuk setiap masing-masing pemasok dan criteria sebagai masukan, maka matriks keputusan dapat ditunjukkan pada tabel 1 .

Tabel 1. Matrik Keputusan

\begin{tabular}{|l|c|c|c|c|c|}
\hline Consultan & $\begin{array}{c}\text { Comercial } \\
\text { by } \\
\text { Costumer }\end{array}$ & $\begin{array}{c}\text { Technical } \\
\text { Proposal }\end{array}$ & Experience & $\begin{array}{c}\text { Work Plan \& } \\
\text { Methodology }\end{array}$ & $\begin{array}{c}\text { Staff } \\
\text { Competence }\end{array}$ \\
\hline DEI & 0.74 & 44.44 & 23.98 & 12.9 & 21.6 \\
\hline HP & 0.67 & 52.32 & 21.88 & 18.3 & 34.7 \\
\hline KSP & 1 & 68.5 & 25.55 & 24 & 54.15 \\
\hline
\end{tabular}

\section{B. Normalisasi Matriks Keputusan}

Dengan menggunakan persamaan normalisasi untuk matrik keputusan, maka dapat dibuat tabel baru yaitu tabel 2 yang merupakan hasil dari normalisasi matrik keputusan.

Tabel 2. Normalisasi Matrik keputusan

\begin{tabular}{|l|r|r|r|r|r|}
\hline Consultan & $\begin{array}{c}\text { Comercial } \\
\text { by } \\
\text { Costumer }\end{array}$ & $\begin{array}{c}\text { Technical } \\
\text { Proposal }\end{array}$ & Experience & $\begin{array}{c}\text { Work Plan \& } \\
\text { Methodology }\end{array}$ & $\begin{array}{c}\text { Staff } \\
\text { Competence }\end{array}$ \\
\hline DEI & 0.01312 & 0.78763 & 0.42501 & 0.22863 & 0.38283 \\
\hline HP & 0.00972 & 0.75870 & 0.31728 & 0.26537 & 0.50319 \\
\hline KSP & 0.01063 & 0.72797 & 0.27153 & 0.25506 & 0.57547 \\
\hline
\end{tabular}

\section{Pembobotan dari Normalisasi Matriks Keputusan}

Pembobotan dilakukan berdasarkan criteria terpenting menurut pengguna.Pembobotan tersebut dapat dilihat pada tabel 3 .

Tabel 3. Pembobotan criteria menurut pengguna

\begin{tabular}{|c|c|c|c|c|c|}
\hline Item & $\begin{array}{c}\text { Comercial by } \\
\text { Costumer }\end{array}$ & $\begin{array}{c}\text { Technical } \\
\text { Proposal }\end{array}$ & Experience & $\begin{array}{c}\text { Work Plan \& } \\
\text { Methodology }\end{array}$ & $\begin{array}{c}\text { Staff } \\
\text { Competence }\end{array}$ \\
\hline Linguistic Weight Interval & 3 & 1 & 5 & 2 & 4 \\
\hline
\end{tabular}

Dengan menggunakan nilai bobot menurut kriteria yang paling penting, kemudian matrik keputusan yang di normalisasi dihitung kembali seperti yang ditunjukkan pada tabel 4 .

Table 4. Pembobotan matrik keputusan yang telah di normalisasi

\begin{tabular}{|c|c|c|c|c|c|}
\hline Konsultan & $\begin{array}{c}\text { Commercial } \\
\text { by Customer }\end{array}$ & $\begin{array}{c}\text { Technical } \\
\text { Proposal }\end{array}$ & Experience & $\begin{array}{c}\text { Work Plan \& } \\
\text { Methodology }\end{array}$ & $\begin{array}{c}\text { Staff } \\
\text { Competency }\end{array}$ \\
\hline DEI & 0.03935 & 0.78763 & 2.12505 & 0.45727 & 1.53131 \\
\hline HP & 0.02915 & 0.75870 & 1.58642 & 0.53074 & 2.01275 \\
\hline KSP & 0.03188 & 0.72797 & 1.35764 & 0.51011 & 2.30188 \\
\hline
\end{tabular}




\section{Untuk Solusi Ideal Positif}

Menggunakan bobot dari matrik keputusan yang telah di normalisasi maka solusi ideal positif ditunjukkan di bawah ini,

$\mathrm{y} 1+=\min \{0.03935 ; 0.02915 ; 0.03188\}=0.02915$

$\mathrm{y} 2+=\max \{0.78763 ; 0.75870 ; 0.72797\}=0.78763$

$\mathrm{y} 3+=\max \{2.12505 ; 1.58642 ; 1.35764\}=2.12505$

$\mathrm{y} 4+=\max \{0.45727 ; 0.53074 ; 0.51011\}=0.53074$

$\mathrm{y} 5+=\max \{1.53131 ; 2.01275 ; 2.30188\}=2.30188$

sehingga untuk solusi ideal positif menjadi,

$\mathrm{A}+=\{0.02915 ; \quad 0.78763 ; 2.12505 ; 0.53074 ; 2.30188\}$

\section{Untuk Solusi Ideal Negatif}

Menggunakan bobot dari matrik keputusan yang telah di normalisasi maka solusi ideal negative ditunjukkan di bawah ini:

$\mathrm{y} 1-=\max \{0.03935 ; 0.02915 ; 0.03188\}=0.03935$

$\mathrm{y} 2-=\min \{0.78763 ; 0.75870 ; 0.72797\}=0.72797$

$\mathrm{y} 3-=\min \{2.12505 ; 1.58642 ; 1.35764\}=1.35764$

$\mathrm{y} 4-=\min \{0.45727 ; 0.53074 ; 0.51011\}=0.45727$

$\mathrm{y} 5-=\min \{1.53131 ; 2.01275 ; 2.30188\}=1.53131$

sehingga untuk solusi ideal Negatif menjadi,

$$
\text { A- }=\{0.03935 ; 0.72797 ; 1.35764 ; 0.45727 ; 1.53131\}
$$

\section{Jarak Untuk Solusi Ideal Positif}

Menggunakan alternative terbaik, jarak antara alternative sasaran dengan criteria memiliki dampak yang paling positif (terbaik, lihat pada Gambar 1) ditunjukkan di bawah ini,

$d+=\left\{\begin{array}{l}0.77413 \\ 0.61201 \\ 0.77001\end{array}\right.$

\section{Jarak Untuk Solusi Ideal Negatif}

Menggunakan alternative terburuk, jarak antara alternative sasaran dengan criteria memiliki dampak yang paling negative (terburuk, lihat pada Gambar 1) ditunjukkan di bawah ini,

$d-=\left\{\begin{array}{l}0.76972 \\ 0.53904 \\ 0.77241\end{array}\right.$ 


\section{Koefisien kedekatan}

Menggunakan jarak alternative terburuk dan jarak alternative terbaik, koefisien kedekatan dihitung agar dapat menampilkan kinerja pemasok yang terbaik (lihat pada Gambar 1) seperti yang ditunjukkan di bawah ini:

Supplier DEI $=0.49857$

Supplier HP $=0.46830$

Supplier KSP $=0.50078$

\section{KESIMPULAN}

Berdasarkan hasil pengamatan dan pengolahan data maka algoritma FUZZY TOPSIS dapat digunakan secara terintegrasi dengan sistem ERP dalam meningkatkan efektivitas sistem. Tujuannya adalah untuk meminimalkan keputusan manusia dari memilih pemasok terbaik. Sehingga dapat diperoleh kesimpulan sebagai berikut:

- Pada penelitian ini pemasok KSP didapatkan sebagai pemasok terbaik dengan nilai 0.50078 dan itu dipilih secara otomatis menggunakan algoritma FUZZY TOPSIS berdasarkan criteria terpenting pengguna seperti yang dinyatakan sebelumnya

\section{SARAN}

Beberapa saran yang dapat meningkatkan proses pemilihan pemasok di dalam Perusahaan Pengolahan Air Kabupaten Tangerang adalah:

- Meningkatkan proses pemilihan pemasok dengan cara mengimplementasikan pengolahan data dengan menggunakan FUZZY TOPSIS sehingga dapat mempercepat proses kerja di departemen pengadaan.

- Memastikan bahwa data yang didapatkan valid sehingga data yang diolah dapat dihasilkan keputusan yang terbaik.

\section{DAFTAR PUSTAKA}

Arini, D. (2015). Analisis Pemilihan Vendor Dengan Menggunakan Pendekatan Metode Fuzzy Topsis Di Pt. Tripatra Engineers And Constructors. Jakarta: Jurnal Ilmiah Teknik Industri Universitas Mercubuana.

Daneshvar, B.., Babek, R.., \& Eko, T. (2014). Supplier selection using integrated fuzzy TOPSIS and MCGP : a case study. Procedia - Social and Behavioral Sciences.

Fasanghari, M.., Gholamy, N.., Chaharsooghi, S. K.., Qadami, S.., \& Soltani, M. (2008). The Fuzzy Evaluation of E-Commerce Customer Satisfaction Utilizing Fuzzy. World Applied Sciences Journal.

Fedrizzi, M.., \& Molinari, A. (2013). A Multi-Expert Fuzzy TOPSIS-based Model for the Evaluation of e-Learning Paths. Italy: 8th Conference of the European Society for Fuzzy Logic and Technology (EUSFLAT).

Kar, M. B.., Chatterjee, K.., \& Kar, S. (2014). A Network-TOPSIS based fuzzy decision support system for supplier selection in risky supply chain. India: IEEE International Conference.

Madi, E. N.., \& Tap, A. O. (2011). Fuzzy TOPSIS Method in the Selection of Investment Boards by Incorporating Operational Risks. United Kingdom: Proceedings of The World Congress on Engineering.

Madi, E. N.., Wagner, C.., Garibaldi, J. M.., \& Wagner, C. (2015). A comparison between two types of Fuzzy TOPSIS Method A comparison between two types of Fuzzy TOPSIS Method. United Kingdom: IEEE International Conference. 
Sodhi, B.., \& Prabhakar, T. V. (2016). A Simplified Description of Fuzzy TOPSIS. India: Dept. Computer Science and Engineering IIT Kanpur.

Soloukdar, A.., \& Parpanchi, S. A. (2015). Comparing fuzzy AHP and fuzzy TOPSIS for evaluation of business intelligence vendors. Decision Science Letters. 
